\title{
The nucleus basalis of Meynert in 20 definite cases of Creutzfeldt-Jakob disease
}

\author{
L CARTIER,* R VERDUGO,* C VERGARA,* S GALVEZ† \\ From the Laboratory of Neuropathology, Department of Neurological Sciences, Facultad de Medicina, \\ Universidad de Chile* and Department of Neurology, Instituto de Neurocirugia e Investigaciones Cerebrales \\ Alfonso Asenjo, $†$ Santiago de Chile, Chile
}

SUMMARY The population of neurons and the neuronal size in the nucleus basalis of Meynert (nbM) were studied in 20 patients with definite Creutzfeldt-Jakob disease (CJD). When compared with a normal control group, the 20 CJD brains showed a significant loss of neurons and reduction of neuronal size, mainly in the middle level of the nbM and mostly affecting the right side. Since these findings show some parallelism with the amount of cortical damage and given the scarce gliosis and spongiosis found in only six of the $20 \mathrm{CJD}$ brains, we postulate that the involvement of the nbM in CJD is a retrograde abnormality secondary to the damage of the neocortex.

After the demonstration that patients with Alzheimer's disease (AD) show a significantly decreased neocortical choline acetyltransferase activity associated with marked cell loss and degeneration of the nucleus basalis of Meynert (nbM),${ }^{1-4}$ an increasing interest concerning the histopathological study of this nucleus, considered as the main cholinergic input to the neocortex, has been focused on other neurological diseases with and without dementia. ${ }^{5-8}$ Since there are few reports describing the neuropathological changes of the nbM, and those were in a small number of cases of Creutzfeldt-Jakob disease (CJD), ${ }^{9-12}$ a transmissible dementia showing a high prevalence in Chile, ${ }^{13}$ we present here the neuropathological findings in the nbM of 20 verified cases of CJD.

\section{Materials and methods}

We studied formalin-fixed brains from 20 cases of definite CJD that were preserved in the neuropathology laboratory. Ten were males and 10 were females, with a mean age at death of 58.5 years, ranging from 39 to 73 years and a mean total duration illness of 5.5 months, ranging from 1.5 to 9 months. In addition to the histologically proven diagnosis, four of the 20 cases had been experimentally transmitted to laboratory animals. ${ }^{14}$ A case control group consisted of brains from three males and three females who died of non neurological

\footnotetext{
Address for reprint requests: Dr Cartier, Departamento de Ciencias Neurológicas, División Oriente. Facultad de Medicina de la Universidad de Chile, PO Box 16117, Correo 9, Providencia, Santiago de Chile, Chile.
}

Received 17 June 1988 and in revised form 10 October 1988. Accepted 17 October 1988 diseases and without dementia, with a mean age at death of 61.8 years, ranging from 46 to 76 years.

In each case one block of $7 \times 10 \times 25 \mathrm{~mm}$ of the basal forebrain was obtained from both cerebral hemispheres by cutting behind the optic chiasm, in front of the mamillary bodies, at $10 \mathrm{~mm}$ from the subarachnoid space over the anterior commissure and $25 \mathrm{~mm}$ lateral to the third ventricle through the putamen, as described by Hedreen $e t$ al. ${ }^{15}$ Since some of CJD brains had been previously used in other investigations, we studied the parts of the blocks that were still available. The anterior, middle and posterior regions of the nbM were identified according to Gorry's description, ${ }^{16}$ while the anteromedial and anterolateral regions determined by Mesulam $e t a l^{7}$ in the rhesus monkey were often impossible to identify. Hence, the anterior region was considered as a whole.

Paraffin-embedded sections $15 \mu \mathrm{m}$ thick were obtained, and at least $\mathbf{3 0}$ sections from each hemisphere including the three regions of the nbM were studied by the cresyl violet stain method. For the total neuronal count we selected two sections from the anterior region, four sections from the middle region and two sections from the posterior region. In each slide we took photographs of $2 \times 3 \mathrm{~mm}$ area showing the highest cell density at $\times 40$ magnification. The cell counting was conducted on a blind basis by two independent observers using photographs projected on a checkered screen. The counts performed by each observer were highly correlated $(r=0.847)(p<0.001)$ and the slope for the straight line obtained was 0.965 .

All neurons with a diameter of $30 \mu \mathrm{m}$ or more were counted regardless of any morphological alteration and the results were separately compared for the right and left hemispheres by a nested analysis of variance. ${ }^{18}$ Since most of the projections to the neocortex arise from the middle region of the nbM, we selected a slide of the right or left middle region showing the maximum cell density and the greater 
The nucleus basalis of Meynert in 20 definite cases of Creutzfeldt-Jakob disease

Table 1 Cell counts in the right and left nucleus basalis of Meynert in controls and in Creutzfeldt-Jakob disease brains

\begin{tabular}{|c|c|c|c|c|c|c|c|c|c|}
\hline \multirow{5}{*}{$\begin{array}{l}\text { controls } \\
\text { CJD }\end{array}$} & \multicolumn{3}{|c|}{$\begin{array}{l}\text { Right } \\
\text { Anterior }\end{array}$} & \multicolumn{3}{|c|}{ Middle } & \multicolumn{3}{|c|}{ Posterior } \\
\hline & $n$ & $\bar{X}$ & $S D^{*}$ & $n$ & $\bar{X}$ & $S D^{*}$ & $n$ & $\bar{X}$ & $S D^{*}$ \\
\hline & $\begin{array}{l}10 \\
23\end{array}$ & $\begin{array}{l}261 \cdot 6 \\
152.2\end{array}$ & $\begin{array}{r}119.7 \\
43.6\end{array}$ & $\begin{array}{l}24 \\
47\end{array}$ & $\begin{array}{l}313.5 \\
144.9\end{array}$ & $\begin{array}{l}65 \cdot 7 \\
44 \cdot 8\end{array}$ & $\begin{array}{l}12 \\
24\end{array}$ & $\begin{array}{l}218 \cdot 1 \\
107 \cdot 0\end{array}$ & $\begin{array}{l}93.5 \\
42.9\end{array}$ \\
\hline & \multicolumn{3}{|c|}{$\begin{array}{l}\text { Left } \\
\text { Anterior }\end{array}$} & \multicolumn{3}{|c|}{ Middle } & \multicolumn{3}{|c|}{ Posterior } \\
\hline & $n$ & $\bar{X}$ & $S D^{*}$ & $n$ & $\bar{X}$ & $S D^{*}$ & $n$ & $\bar{X}$ & $S D^{*}$ \\
\hline $\begin{array}{l}\text { controls } \\
\text { CJD }\end{array}$ & $\begin{array}{l}12 \\
24\end{array}$ & $\begin{array}{l}267 \cdot 3 \\
160 \cdot 0\end{array}$ & $\begin{array}{l}55 \cdot 3 \\
45 \cdot 5\end{array}$ & $\begin{array}{l}24 \\
38\end{array}$ & $\begin{array}{l}294.5 \\
178.5\end{array}$ & $\begin{array}{l}62 \cdot 0 \\
38 \cdot 2\end{array}$ & $\begin{array}{l}12 \\
15\end{array}$ & $\begin{array}{l}214.3 \\
155.8\end{array}$ & $\begin{array}{l}63.0 \\
50.0\end{array}$ \\
\hline
\end{tabular}

$\mathrm{n}=$ number of sections

* $p<0.001$.

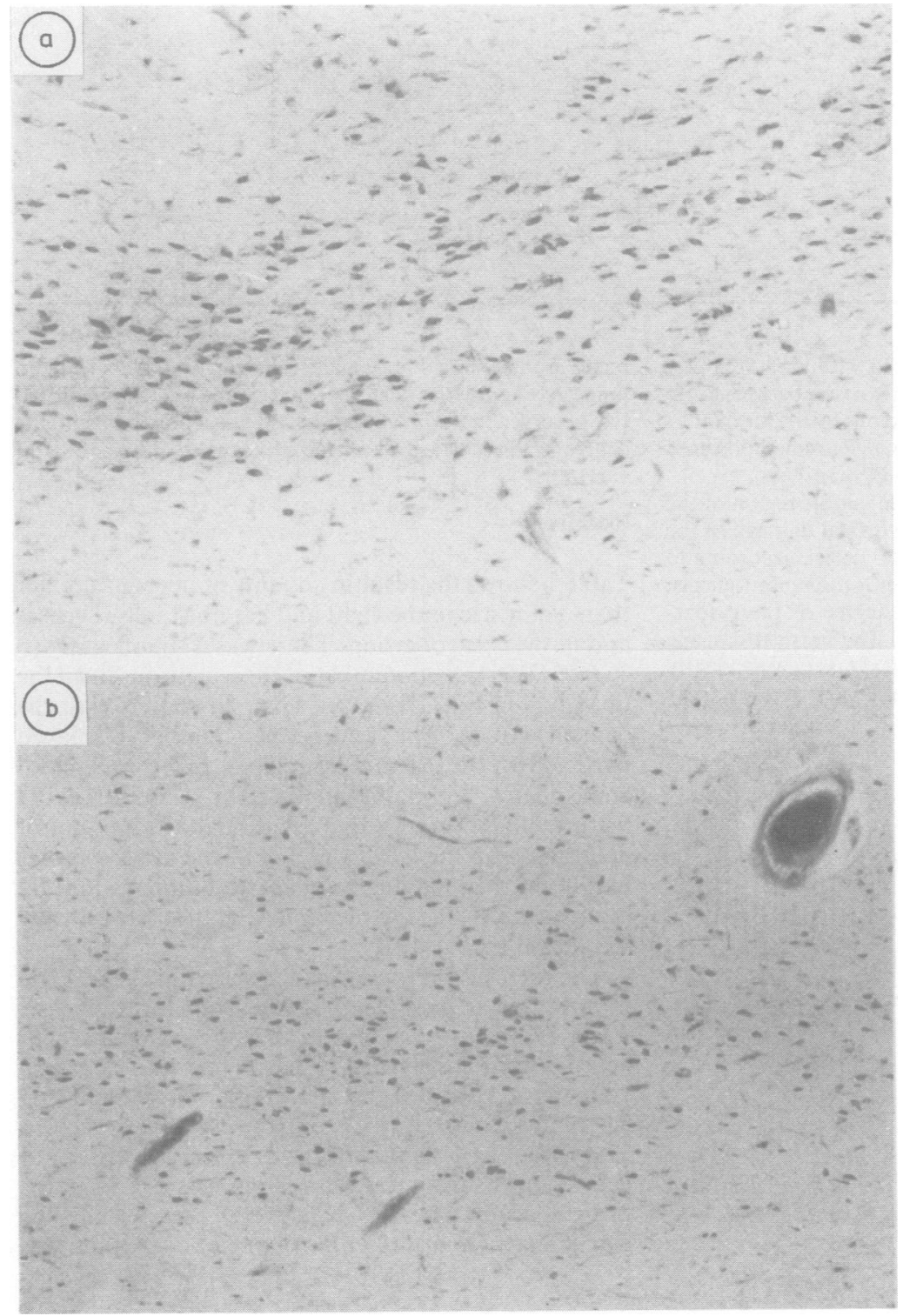

Fig 1 Middle region of the right nucleus basalis of Meynert in a normal control brain $(a)$ and in a case of Creutzfeldt-Jakob disease (b) showing overall flattening of the nucleus and diminished number and size of neuron cells (cresyl violet $).(\times 40)$ 
Table 2 Individual cell count in the nucleus basalis of Meynert in controls and in Creutzfeldt-Jakob disease cases correlated with the cortical damage

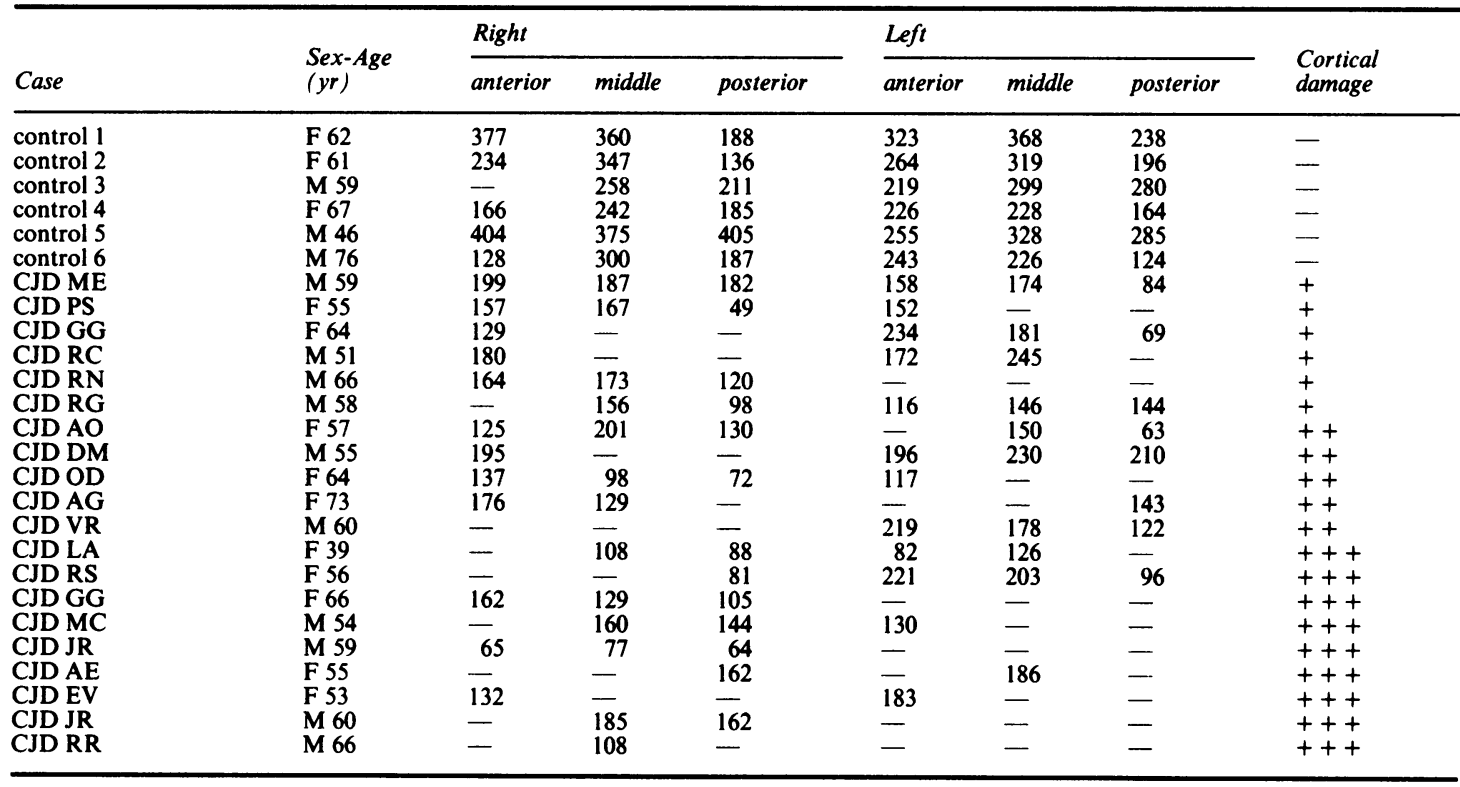

diameters of all neurons were measured within an area of 1 $\mathrm{mm}^{2}$ in the centre of the slide. The comparison between CJD cases and the control group was carried out by the Student's $t$ test for independent samples. Additional stain methods used were haematoxylin-eosin, Bodian and Bodian-Nissl.

In 19 of the 20 CJD brains where the middle region of the nbM was available we evaluated the cortical damage of the frontal, parietal, temporal and occipital cortex according to the amount of spongiform change, neuron loss and gliosis, particularly taking into account the degree of the cytoarchitectural disturbance of the cortex. The cortical damage was defined as: $(+)$ when all the cortical layers were clearly recognisable; $(++)$ when the cortical layers were partially
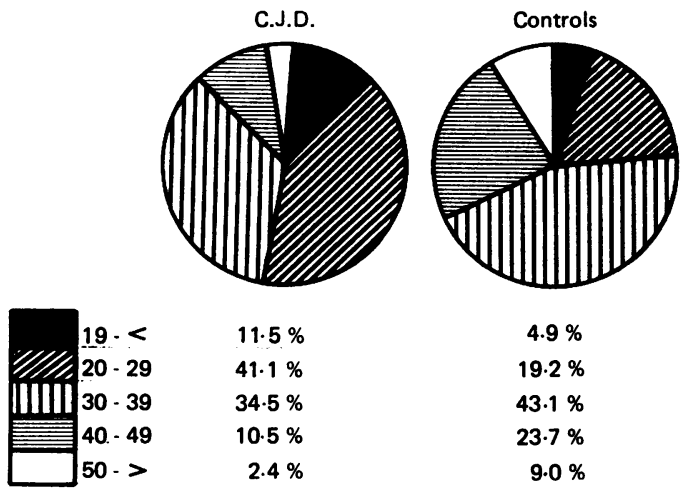

$$
\begin{array}{r}
11.5 \% \\
41.1 \% \\
34.5 \% \\
10.5 \% \\
2.4 \%
\end{array}
$$

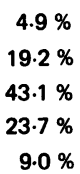

Fig 2 Percentage of different neuron size in the middle region of the nucleus basalis of Meynert in controls and Creutzfeldt-Jakob disease brains. recognisable, and $(+++)$ when the cortical layers were no longer recognisable. The neuronal count and the neuronal size observed in the nbM were statistically compared with the degree of the cortical damage by means of the analysis of variance.

\section{Results}

Table 1 shows the resulting counts of neurons greater than $30 \mu \mathrm{m}$ size in the right and left nbM in CJD cases and in the control group. There was a significantly ( $p$ $<0.001$ ) decreased number of those neurons in all the nbM regions of CJD cases when compared with the control group. The lower cells number displayed particularly by the middle regions in both cerebral hemispheres, but mainly in the right, is a noteworthy feature of CJD cases (fig 1). Although the amount of neuron loss in the middle region of the $n b M$ is rather paralleled with the degree of cortical damage in CJD brains (table 2), this tendency is not statistically significant $(p>0 \cdot 10)$.

The total of 2411 neurons measured in the 20 CJD brains gives an average of 126 neurons for each case, while in the six control brains the 825 measured neurons give an average of 138 . The mean neuronal diameter in the nbM of CJD brains was $28.9 \mu \mathrm{m}$ (SD 8.8 ), while in the control group brains the average was $35 \mu \mathrm{m}$ (SD 7.1). As shown in fig 2, the percentage of neurons measuring less than $30 \mu \mathrm{m}$ was $24 \cdot 1 \%$ in the control group and $52.6 \%$ in CJD cases, while the percentage of neurons with a diameter over $30 \mu \mathrm{m}$ was 


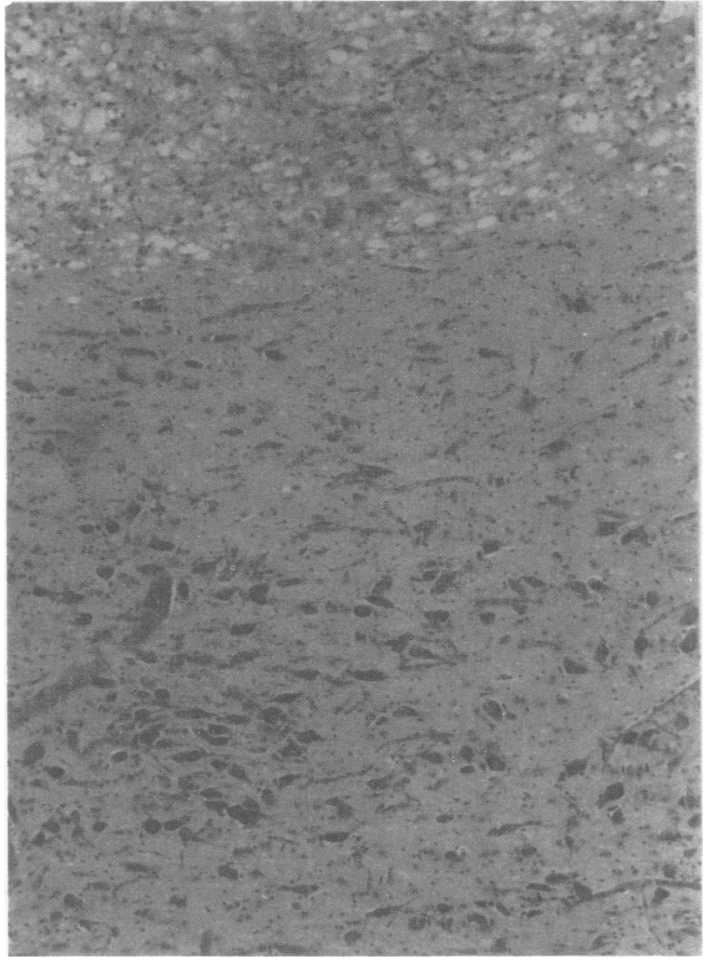

Fig 3 Creutzfeldt-Jakob disease case. Spongiosis of the innominate substance without involvement of the nucleus basalis of Meynert. Gliosis and decreased size of neurons in the middle region (cresyl violet). ( $\times 100)$
$75.8 \%$ and $47.4 \%$, respectively. In addition, there was a significant correlation $(p<0.0001)$ between the mean neuronal size in the middle region of the nbM and the amount of the cortical damage. Thus, the mean neuronal diameter in the nbM was $31.5 \mu \mathrm{m}$ (SD 9.8) in CJD brains with cortical damage $+; 28.9 \mu \mathrm{m}$ (SD 8.4) in CJD brains with cortical damage ++ and $26.8 \mu \mathrm{m}$ (SD 8.1) in CJD brains with cortical damage +++ . On the other hand, no relationship was observed between the decrease of number and size of neurons in the nbM and the total duration of CJD.

In most of CJD brains the nbM had lost its normal fusiform shape, appearing as a retracted, flat and less dense cellular band (see fig 1). Mild spongiform change affecting the nbM was observed in only two cases. In another four there was spongiosis of the innominate substance without evident involvement of the nbM (fig 3). Haematoxylin-eosin stains showed marked glial proliferation in the nbM of two of the 20 CJD brains, while moderate gliosis was observed in another four cases.

A remarkable neuropathological feature displayed by the nbM in all CJD brains was the rounded shape of most of the neurons, showing intracytoplasmic vacuoles with a tendency to aggregate, displacing the nucleus and conferring a foamy aspect on the affected neurons (fig 4). In addition, fine intra- and extravacuolar granules reminiscent of the hippocampal granulo-vacuolar degeneration were also present within the neurons, although showing different staining characteristics.

Staining by the Bodian method showed a diminished number of fibres and thickened and curled degenerated axons. Scant neurofibrillary tangles were

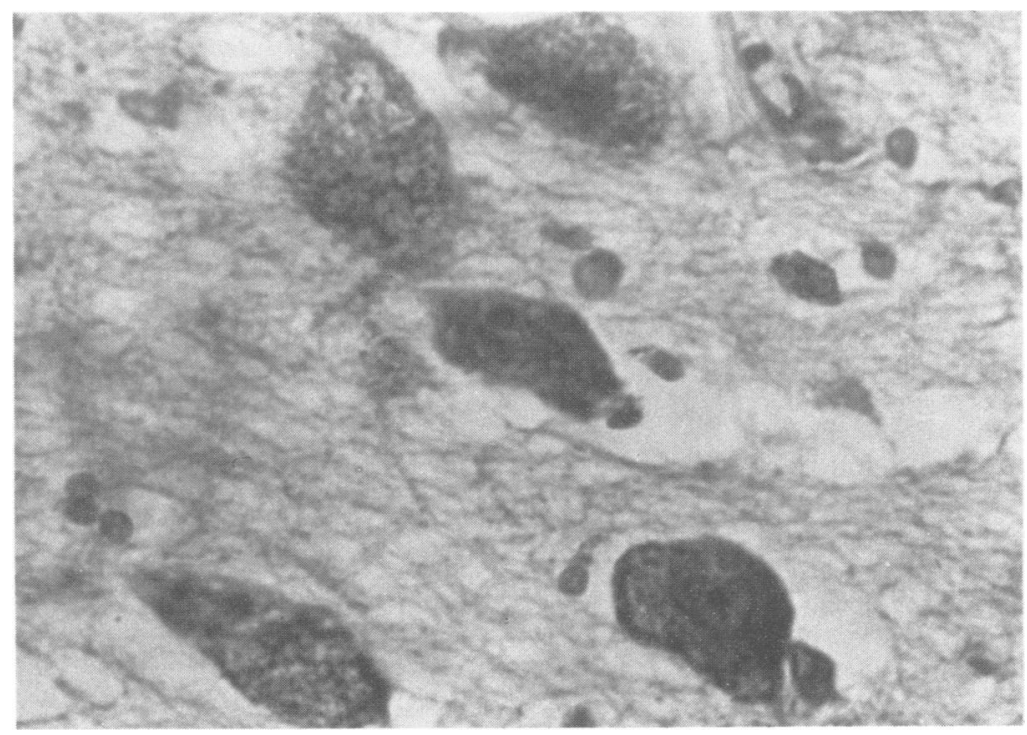

Fig 4 Creutzfeldt-Jakob disease case. Roundness and vacuolisation of neurons in the middle region of the right nucleus basalis of Meynert (cresyl violet). $(\times 400)$ 
demonstrated in the nbM of two CJD patients aged 60 and 66 years, respectively.

\section{Discussion}

The study of the nbM in our 20 CJD cases shows a substantially diminished number of those neurons with a diameter over $30 \mu \mathrm{m}$, which correspond to most of the cholinergic neurons, ${ }^{19}$ while a decreased size of all neurons was observed in an area studied in the middle region of the nbM, in sharp contrast to the scarce gliosis and spongiosis that characterise CJD.

The decreased number of neurons greater than $30 \mu \mathrm{m}$ found preferentially in the middle region of the nbM in our 20 CJD brains agrees in part with the observation of Roger $e t \mathrm{al}^{9}$ who described an intermediate decreased neuronal population of the $\mathrm{nbM}$ in five CJD cases, although mostly affecting the anterior region. In addition, in the patient of Arendt et $a^{10}$ a maximum loss of neurons was observed in those parts of the nbM projecting to the most severely damaged cortical areas. This is also in agreement with our findings, since the middle region of the nbM projects principally to the neocortex. On the contrary, the two CJD cases studied by Cutler et al ${ }^{~ 11}$ and by Clark et al ${ }^{12}$ did not show neuron loss in either region of the nbM.

Although the prevalence of morphological changes in the right nbM of some of our CJD cases is difficult to interpret, it is tempting to consider this morphological asymmetry in the light of the controversial functional asymmetry of cholinergic activity that has been described in some normal and pathological brains. ${ }^{2021}$

The high percentage of neurons smaller than $30 \mu \mathrm{m}$ that was found in an area of the middle region of the nbM is remarkable in our CJD cases. Since the measurement of neurons was performed in an area with the largest cell density, the number of neurons measured in each CJD and control brains were alike. This and the flat and less dense aspect of the nbM in CJD brains shows that in addition to neuron loss, there is a consistent reduction in neurons size. However, it is not possible to prove whether the number of neurons smaller than $30 \mu \mathrm{m}$ size does not change.

The neuronal alterations described above in the present cases are comparable to similar findings reported by Pearson $e t a^{22}$ in monkeys and humans after cortical ablations and by Sofroniew $e a^{23}$ in rat brains following cortical injuries. This and the relationship observed between the reduced size of neurons in the nbM and the intensity of the cortical damage highly suggest that the neuronal alterations of the nbM in CJD cases are secondary to the cortical lesions. Thus, it is probable that in CJD the cortical synapses are not specifically affected through the primary damage in the regions of membrane apposition, ${ }^{24}$ leading to a retrograde involvement of the nbM. Conversely, a specific and perhaps pathogenic involvement of presynaptic cholinergic cortical terminals has been hypothesised in patients with AD. ${ }^{4526}$ An additional support for the hypothesis of a secondary damage of the nbM in CJD patients is the scarce gliosis and spongiosis displayed by this nucleus, in sharp contrast with that observed in the cerebral cortex of our 20 CJD cases.

The lack of relationship between the intensity of the histopathological changes of the nbM in CJD cases and the total duration of the disease does not rule out the hypothesis of a retrograde degeneration of the $\mathrm{nbM}$, since the intensity of the cortical damage is related to the anatomoclinical form of the disease rather than to its total duration. ${ }^{27}$

In accord with the hypothesis proposed by Clark et $a l,{ }^{7}$ the dementing processes can be classified into two groups. First, those associated with a severe decrease of cortical cholinergic activity and a significant loss of nbM neurons, as occurs in AD patients. Second, those without impairment of the cortical cholinergic activity and with an unharmed nbM, as in Huntington's disease. Nevertheless, we believe that it is also important to determine if the changes in the nbM observed in some dementing diseases, such as CJD, is either primary or secondary to the cortical damage.

\section{References}

1 Whitehouse PJ, Price DL, Clark AW, Coyle JT, DeLong MR Alzheimer's disease: evidence for selective loss of cholinergic neurons in the nucleus basalis. Ann Neurol 1981;10:122-6.

2 Tagliavini F, Pilleri G. Neuronal counts in the nucleus of Meynert on Alzheimer's disease and in simple senile dementia. Lancet 1983;i:469-70.

3 Coyle JR, Price DL, DeLong MR. Alzheimer's disease: a disorder of cortical cholinergic innervation. Science 1983;219:1184-90.

4 Fishman EB, Siek GC, MacCallum RD, Bird ED, Volicer L, Marquis JK. Distribution of the molecular forms of acetylcholinesterase in human brain alterations in dementia of the Alzheimer type. Ann Neurol 1986;19:246-52.

5 Arendt T, Bigl V, Arendt A, Tennstedt A. Loss of neurons in the nucleus basalis of Meynert in Alzheimer's disease, Paralysis agitans and Korsakoff's disease. Acta Neuropathol 1983; 61:101-8.

6 Nakano I, Hirano A. Parkinson's disease: neuron loss in the nucleus basalis without concomitant Alzheimer's disease. Ann Neurol 1984;15:415-8.

7 Clark AW, Parhad IM, Folstein SE, et al. The nucleus basalis in Huntington's disease. Neurology 1983;33:1262-7.

8 Whitehouse PJ, Hedreen JC, White CL. Basal forebrain neurons in the dementia of Parkinson disease. Ann Neurol 1981;10:122-6.

9 Rogers JD, Brogan D, Mirra SS. The nucleus basalis of Meynert in neurological disease: a quantitative morphological study. Ann Neurol 1985; 17:163-70.

10 Arendt T, Bigl V, Arendt A. Neurone loss in the nucleus basalis of Meynert in Creutzfeldt-Jakob disease. Acta Neuropathol 1984;65:85-88.

11 Cutler NR, Brown PW, Narayan T, Parisi SE, Janotta F, Baron H. Creutzfeldt-Jakob disease: a case of 16 years duration. Ann 
Neurol 1984;15:107-10.

12 Clark AW, Lehmann J, Whitehouse PJ, Struble RG, Coyle JT, Price DL. Cortico-striato-spinal degeneration (CSSD) mimicking Alzheimer's disease: studies of the nucleus basalis of Meynert and cortical choline acetyltransferase. $J$ Neuropathol Exp Neurol 1983;42:334.

13 Gálvez S, Masters CL, Gajdusek DC. Descriptive epidemiology of Creutzfeldt-Jakob disease in Chile. Arch Neurol 1980;37:11-14.

14 Gálvez S, Cartier L, Gajdusek DC, Asher D, Gibbs CJ, Jr, Lampert $P$. Transmisión experimental de ocho casos de enfermedad de Creutzfeldt-Jakob al animal de laboratorio. Rev Chil Neuro-Psiquiat 1984;22:285-91.

15 Hedreen JC, Struble RG, Whitehouse PJ, Price DL. Topography of the magnocellular basal forebrain system in human brain. J Neuropathol Exp Neurol 1984;43:1-21.

16 Gorry JR. Studies on the comparative anatomy of the ganglion basale of Meynert. Acta Anat 1963;55:51-104.

17 Mesulam MM, Mufson EJ, Levey AI, Wainer BH. Cholinergic innervation of cortex by the basal forebrain: cytochemistry and cortical connections of the septal area, diagonal band nuclei, nucleus basalis, and hypothalamus in the rhesus monkey. $J$ Comp Neurol 1983;214:170-97.

18 Snedecor GW, Cochrane WG. Statistical Methods. Iowa State University Press, 1972.

19 Parent A, Poirier L, Boucher R, Butcher LL. Morphological characteristics of acetylcholinesterase-containing neurons in the
CNS of DFP-treated monkeys. J Neurol Sci 1977;32:9-28.

20 Amaduci L, Sorbi S, Albanese A, Gainotti G. Choline acetyltransferase (ChAT) activity differs in right and left human temporal lobes. Neurology 1981;31:799-805.

21 Zubenko GS, Moossy J, Hanin I, Martinez AJ, Rao GT, Kopp U. Bilateral symmetry of cholinergic deficits in Alzheimer's disease. Arch Neurol 1988;45:255-9.

22 Pearson RCA, Gatter KC, Powell TPS. Retrograde cell degeneration in the basal nucleus in monkey and man. Brain Res 1983;261:321-6.

23 Sofroniew MV, Pearson RCA, Eckenstein F, Cuello AC, Powell TPS. Retrograde changes in cholinergic neurons in the basal forebrain of the rat following cortical damage. Brain Res 1983;289:370-4.

24 Beck E, Daniel PM, Davey DC, Gajdusek DC, Gibbs CJ Jr. The pathogenesis of transmissible spongiform encephalopathy. Brain 1982;105:755-86.

25 Sheu KR, Kim Y, Blass JP, Weksler ME. An immunochemical study of the pyruvate dehydrogenase deficit in Alzheimer's disease brain. Ann Neurol 1985;17:444-9.

26 Whitehouse PJ, Rajagopalan R, Kitt CA, et al. Muscarinic cholinergic receptors in the amygdala in Alzheimer's disease. Neurology 1984;34:121.

27 Gálvez S, Cartier L. Análisis clínico de una serie de 69 casos definitivos de enfermedad de Creutzfeldt-Jakob ocurridos en Chile entre 1960 y 1985. Rev Med Chile 1987;115:1148-54. 